\title{
Exploring the Origin of Female Concept and Image in the Works of Sun Li
}

\author{
Mengyao Zhou \\ Northwest University \\ Xi'an, China 710000
}

\begin{abstract}
Sun Li's novels and other works mostly take females as the eulogizing objects, build up a "Mountain Blue" series of female images and are recognized as a master of femininity school in revolutionary literature. For Sun Li, females are the aesthetic objects of his works and the sources of his artistic inspiration. Female and beauty are similar. Sun Li's female concept not only reflects his understanding of female's beauty, but also has distinctive features as it is relevant to his own character and the anti-Japanese war. Moreover, Sun Li's female concept also contains his rational thinking about the contemporary reconstruction of national cultural traditions.
\end{abstract}

Keywords-Sun Li; female concept; female image; female beauty

\section{INTRODUCTION}

Theological aesthetics believes that "the reason why the form or image of beauty is beautiful is because of such a huge charm emitted from its intrinsic nature that creates an image of beauty." It is charm that distinguishes beauty from non-beauty. Why we say that the female images in Sun Li's early novels are beautiful is right because of the good charm of human nature shining on their body. It embodies the unity of "double life" and "double nature" of human beings, that is, a harmonious co-existing of physical life, spiritual life and social life of human beings. In the difficult struggling against the enemy, females not only remained their beauty but also rediscovered their own meanings in the anti-Japanese activities such as labor, leading the way, breaking the road and learning; they broken through the constraints imposed on female for thousands of years and created a brand new life value. Sun $\mathrm{Li}$ appreciates the optimistic and uplifting spirit of females in the arduous years and thinks that it is an important guarantee for the victory of China. Sun Li's praise of the ideal character of female reflects his value pursuit.

\section{SUn Li's FEMALE CONCEPT Is INSEPARABLE FROM HIS UNDERSTANDING OF FEMALE BEAUTY}

\section{A. Females Are Beautiful}

Sun Li said that "beauty is always associated with youth, enthusiasm and vitality." The female images of the "Mountain Blue" series he created are either little girls or little daughters-in-law, such as Shuisheng's wife, Ermei, Daling, Erling, Xiaoju, Xiangju, Xiumei, Wu Zhao'er, Niu'er,
Jiu'er... "Mountain blue" is a light blue dried indigo coarse cloth. As described in his "Mountain Memories", "in Tianjin, it looks very prominent and feels rustic. But in Fuping, wearing such a dress, you may look very bright and shining as the weaving and dyeing is not easy to do." Young women are as simple, bright and beautiful as "mountain blue", in line with the Chinese traditional aesthetic standards and male writer's aesthetic psychological needs.

Young women described bySun Li almost look pretty and charming, strong and innocent. Daling and Erling look like "I have never seen such a handsome child", as stated in "Qin and Xiao". In his novel "Wu Zhao'er", Wu Zhao'er "wears a red quilted jacket and a fresh white a fresh white bag leaning on her waist contained three hand grenades." "She seems like a red flower suddenly bloomed in this rocky mountain, floating up a piece of colored cloud." "When we encountered the enemy, Wu Zhao'er would turn the quilted jacket over. The liner of the jacket was white so that she looked like an escaping white goat with blackhead." As written in the "Wheat Harvest", "in order to stop the enemy's advancement, Ermei led a group of young women to dig trenches and destroy roads. They all dressed in new clothes, with clean face and tidy hair and a new towel was covered on head to shield sunshine and wind, just like to visit relatives." As written in his essay "A Week of Living in the Guerrilla Zone", When Cailing gets out of the hiding hole in the ground, "a white felt hat came out of the hole, but the below was a charming girl's face, wearing a plaid coat; when jumping out, what worn on her foot was a pair of men's broken cotton shoes. She sat down, pulled the cotton shoes down and threw them aside, revealing the light blue fashion shoes, and then took off the felt hat and shook the long black soft hair." This beautiful genre painting indicated that war can't destroy people's pursuit of beauty. Even in the cruel years of war, women's love of beauty does not change. After washing away the smoke and dust, they are still beautiful and moving. Sun Li fully praises the enthusiasm and energy of adolescence in life. He believes that "the enthusiasm of youth can not only support all creatures, but also promote any difficult and heavy business." In his essay "Wang Xiangju", the 17 years old Xiangju engaged in the heavy physical work of the watering the garden every day. Although she was too tired to even eat, she could still actively go to the women's group in the evening, as if she had endless power. As the description of the little daughterin-law Qianhua, "She was funny to say something, like a car 
axle lubricated with new oil so that it turns flexibly and emits good sound. This woman was quick with her mouth, foot and hands. She was good at weaving and spinning and was also a good long-term worker in the farmland."

In general, beauty and women are connected and beauty and youth are accompanied. Their beauty is the beauty of youth, the beauty of health and the beauty of action. Their beauty has gained a new interpretation in the Anti-Japanese war of the nation. The eulogizing of the beauty of young women at firstly originated from Sun Li's long-term rural life experience and a special feeling for rural girls. It was more derived from the great power he had experienced in the war, the people's enthusiasm for protecting the motherland and the organization. It was a guarantee for the victory of the war.

\section{B. The Core of Female Beauty Is the Beauty of Character}

In Sun Li's letter to Kang Zhuo in the 1940s he talked about the criteria for looking for a mate: "As long as she is young, has good character, and have good appearance, that's OK." "Good character" is the feature of ideal woman in Sun Li's mind. Psychology believes that character is the stable attitude of people in coping with objective reality, and the psychological characteristics of the corresponding usual behavioral style. Some psychologists in Europe and America often equate the character concept with personality. Sun Li's "good character" refers to the words of Cao Xueqin who he believes in, "In the hearts of girls, there are many kinds of hidden primitive virtues of human beings." In his works, most females are those who he thinks having "virtue". "All true virtues are preserved by the poor working people. All beautiful words and deep thoughts are preserved in the word of mouth of working people". In his female "virtue" theory, there is no lack of distinct value tendency.

The first virtue of female is hard-working. Sun Li recalled that in wheat harvest season his mother was like a crazy labor working for the crops in the field, and even there were a layer and layers of white alkali generated on her blue cloth and pants by sweat (see "Mother's Memory"). His cherished female images include skilled cotton spinner, skilled matting person as well as those who can prop up sled, dig trenches and brake roads like men, lead the way for troops, and participate in all struggles and living affairs. Females in his works often show the enthusiasm and heroic behavior not inferior to men. As described in the opening of his novel "Lotus Shallow Lake", "The moon rises, the yard is very cool and clean and the reed broken in daytime can properly be used for matting. Women sit in the small courtyard, with fingers entangled with silky slender reed. The reed is thin and slender, dancing on the women's arms." Sun Li sublimated the excellent morality of the Chinese nation in a poetic expression.

The second virtue of female is goodness and justice. These women are as kind indeed although they are as rustic as the "mountain blue". Xiaoju in "Monument" and the little girl in "Women" generously took off their cotton coat for rescuing soldiers. Wu Zhao'er in "Wu Zhao'er" quarreled with me at first. After seeing my bare foot, she actively committed to make a pair of cloth socks for me and even more women sent their husbands and sons to join the army and fight. In "Lotus Shallow Lake", Sun Li unwittingly exposed the on-again and righteous composed feelings. When they wanted to go to see their husband away from home, they might find various excuses: someone said that her husband left a cloth; someone said that she has a word to tell her husband; someone said that it's her mother-in-law let her to see her husband and it's not her intrinsic willing. When they failed to find their husband, they might complain again: "You see he just walk away", "how hurry up can he. I even haven't seen him be so hurrying up when he gone through the New Year or married me! ", "even the feasting pillar is not effective", "No, it's gone!" "As soon as he arrived in the army, he might surly forget the family." Obviously, they are comforting their disappointed emotion by virtue of complaining about their husbands. When they witnessed the bravery of their husbands in the battle, their hearts were full of love, but they might say ironically, "how can they ignore us even when seeing us!" "Ah, it seems like we make them feeling shame." "Sister Shuisheng, we should also set up a team after we go back; otherwise, how can we go out later?" The women in Sun Li's works gradually grow up from loving husbands to understanding husbands, and further participating in the war, from loving their families to loving everyone and from loving relatives to loving soldiers. Because they understand that they may lose everything if not going to fight against Japanese. The simple sense is mixed in the beautiful personality and humanity.

\section{THE PECULIARITY IN SUn Li’s FEMALE CONCEPT}

\section{A. Moral Judgment on Female's Beauty and Ugliness}

Judging women's beauty and ugliness from a moral point of view, Sun Li clearly divides women into two types: beauty and ugliness. The ideal women are collection of truth, goodness and beauty. They not only have beautiful appearance, but also have a beautiful heart and noble spiritual realm. On the contrary, most of the backward women are described as those who are ugly in appearance, lazy and sloppy in individuality and backward or even reactionary in politics. As described in his novella "Former Biography of Tiemu", Xiaoman's sister looks ugly and strange, temperamental and very gluttonous. She can come up with all kinds of tricks to satisfy their own gluttonous demand and may quickly sell anything she get, to by something for eating. In "The Story of Lazy Horse", the "lazy wife" is slovenly all day, lazy and gluttonous and makes military shoes perfunctorily so that nobody wants to buy the shoes that she made. In the essay "Qi Manhua", Qi Manhua and her sister are no longer their old selves after getting married due to different living environment. Her sister and brother-in-law often cheat to eat and drink on the village so that they are scorned by people in the village and town; while Qi Manhua and her husband's families are hardworking and simple, gradually living a booming life. In the eyes of Sun Li, the behavior of Manhua's sisters is contrary to the traditional diligence and kindness and the ethics of love and kindness. Marxism believes that morality is the sum of a special behavioral norm that regulates the relationship among people in the social life. It constitutes and 
measures the spiritual power of suppressing evil and promoting goodness for the most profound needs of human beings. Morality lies in the ideological consciousness of human beings, deep into the soul of human beings, guiding people to pursue noble sentiments, noble morality and becoming a moral people. The essence of moral culture is the unity of truth, goodness and beauty and is a critique against the ideology of false, ugly and evil. This is the purpose of Sun Li to beautify idealized female and vituperate backward female. However, Sun Li's criticism of moral consciousness is by no means in super stage. As pointed out in the "Xiangju's Mother", it is impossible to check the weight of "morality" of poor women, because "all misfortunes are caused by poverty". At the same time, there is no lack of goodwill in the critique of moral consciousness. He said that the mountain people are so simple and cute. "For example, the old woman calls my sympathy and has simple and cute heart, although she often plays tricks!" As written in "Carpenter's Daughter", Xiaoxing fallen from an ordinary girl to a "fairy figure" depending men to live. It was the poor life that made the girl's heart distorted. Sun Li deeply feels sorry and sympathy for Xiaoxing's experience.

The outstanding morality of Chinese nation is the carrier of the national spirit on which our nation depends for survival and development. The national spirit is permeated into our moral culture. The great anti-Japanese war and the liberation war provided a big stage for demonstrating the "golden jade quality" of Chinese women and also tested the power of traditional morality contained in many women. Sun $\mathrm{Li}$ said, "When my hometown encountered foreign aggression, I had more clearly seen the noble qualities of the Chinese nation. In the eight years of Anti-Japanese War, I had a deeper understanding of the hardworking and brave character of Chinese farmers. They were dedicated to the sacred Anti-Japanese War. They are witty and optimistic." Sun Li discovered the invincible spiritual power of Chinese nation in those women, granted traditional morality a new connotation and charm and strongly conveyed the general spirit and direction of the times. His works are filled with the emotion of revolutionary optimism everywhere. As written in "A Week of Living in the Guerrilla Zone", when enemy came, women ran to the farmland like a group of frightened birds. When enemy left, they "swept the sweat on their faces and the dust on their hair with their clothes. After calming down and clearing up the clothes, they returned as a large crowd with joy and laughter". "Then, they continued picking up the needle and thread, stepping on the board of weaving machine and rotating the spinning wheel."

\section{B. New View of Female's Life and Spirit}

We can better understand the characteristics of that times when putting Sun Li's female concept into the history of Chinese women's struggling for liberation. Sun Li said, "I think that the reason why new literature mostly describes women is because for thousands of years in China, women's suffering is deeper." With the intensification of ethnic contradictions in 1930s 1940s, the times gave women libration an opportunity to transform. By participating in the war fighting, women went to the society and liberation and finally achieved the conscious combination of anti-feudal ethics and national liberation. In the tide of national liberation, women's subjectivity and life value was reflected to the greatest extent. In "After Going Out", Wang Zhenzhong, who was a strong and sensible girl, was dissatisfied with her family's bad reputation in the village and secretly applied for a health training class held in the Anti-Japanese Families Middle School. Over the efforts, she finally broke off their engagement and happily joined the anti-Japanese team. In "Glory", Xiumei improved her work level and gained real lover inthe process of criticizing and educating Yuansheng's wife. Sun Li enthusiastically praised the great dedication of women in the war. "Many wives sent their husbands and many mothers sent their sons to join the army and take responsibility for raising their families their children; in the years of enemy's mad aggression, young women carried their children and supported their parents inlaw, fleeing from calamity in the windy, frosty and rainy days; in the years lacking of food, they organized mutual production activities to survive in the famine period; they are constantly working while cherishing the memory of the relatives who are fighting in the distance; they carried stretchers, made military footwear, took care of the wounded and hided soldiers; they dared to die than being humiliated by enemy and traitors and held firm stand and brake the feudal personal consideration in the land reform movement. In addition, Sun Li also wrote their psychological course in changing the destiny. For example, Xiangju previously didn't dare to walk through the land edge of the landlord and the gates of landlords, for being afraid of being laughed at her poor cloth and appearance by the ladies and sisters. But now, she enters the gate of the landlord for the first time in a mood of victory (see "Wang Xiangju").

\section{Friend of Females}

Sun $\mathrm{Li}$ seems has a natural connection with female. Every time he went to work in the countryside, he firstly approached local females. This connection can be traced back to his female-centered childhood experience. Jungian believes that people's experiences may be "consumed" by spirit and then transformed into a psychological energy; when a high psychological value is put into a concept or emotion, it means that the concept or emotion has considerable power to affect one's behavior. The psychological characteristics of Sun Li's psychological energy tending to female and having direct effect on him is respecting female.

A sentence in the essay "Xiangju" tells the mystery of Sun Li's female image creation, that is, "She did not complain about the suffering of working. She just told a girl's psychological grievances." In the sketch "Wang Fulu", after Wang Fulu married his husband, once his father came to her family to send the pickax as her dowry. But her husband was not pleasing to look at it and did not pack some cereals in her father's bag but let her father go lonely; another time, her brother came to see her, standing in the yard for all morning without greeting of her families. After sending away her brother, her eyes were red. The description by few words outlined the helplessness and grievance of the 15 or 16 years 
old young married woman, letting us feel a lump came into the throat after reading those words. Even for the backward females, Sun Li is also full of sympathy and understanding. Xiaoman was beautiful and capable. She was good at both indoor and outdoor works and had good relations with people. But she had a very ugly sister and a family with a bad reputation. She went to her sister's family in order to avoid the marriage arranged by her parents. Quickly, she fell in love with the desultory Liuer. She wanted to make progress but also feared to be fight against on the general meeting. When the new marriage law was popularized, she immediately became active, but soon returned to her previous life style because she was worried about their relationship being exposed in checking by the village; she wanted to tell the cadres about her distress, but was again full of worries, wish to speak but stop on a second thought. Xiaoman longed for being permitted by people and policy. She said to the cadres, "You can't just as look at a picture as understanding a people just sit here, even for a short time." Her words reflect complexity and problem in working style of rural work at that time. Xiaoman is a rare "middle character" in Sun Li's works. It reveals the success of realism. If it is not in the position of women, if it is not "putting yourself in her shoes", Xiaoman is easy to be affixed with various labels.

\section{CONCLUSION}

Sun Li's female concept is based on the inner and outer and mental and physical harmony of female, and carries forward the aesthetic ideal of "harmony" of Chinese nation. In our fighting against aggression and struggling for freedom, "harmony" became the inner motivation that concentrated the power of Chinese nation.

\section{REFERENCES}

[1] Continuation of Collected Works of Sun Li. Baihua Literature and Art Publishing House. Vol. 2, 2002. (in Chinese)

[2] Collected Works of Sun Li. Baihua Literature and Art Publishing House. Vol. 3, 2002.(in Chinese)

[3] Continuation of Collected Works of Sun Li. Baihua Literature and Art Publishing House. Vol. 3, 2002.(in Chinese)

[4] Collected Works of Sun Li. Baihua Literature and Art Publishing House. Vol. 4, 2002.(in Chinese)

[5] Continuation of Collected Works of Sun Li. Baihua Literature and Art Publishing House. Vol. 1, 2002.(in Chinese)

[6] A Primer of Jungian Psychology. SDX Joint Publishing Company. 1987. (in Chinese)

[7] Collected Works of Sun Li. Baihua Literature and Art Publishing House. Vol. 5, 2002.(in Chinese) 